\title{
Determining Factors for Success of Banking Digital Transformation
}

\author{
Andi Ilham Said*, Maria Angelita \\ Sekolah Tinggi Manajemen PPM \\ Jakarta, Indonesia \\ *andiilhamsaid@gmail.com
}

\begin{abstract}
Banking industry in Indonesia are facing a problem in the decline of their payment services customer because new financial technology companies (fintech) give continuous discount in their "Cash Burn" strategy to seize banking market. A bank in Indonesia who has seen their payment customer growth decreased, a fact which forces the bank to start a digital transformation. One of the many benefits of the transformation is reduced operational costs. Based on the Digital Transformation Playbook by Rogers, the bank needed to review their strategic thinking in 5 domains, namely CC-DIV (Customer, Competition, Data, Innovation, Value) and increase their organizational agility. The research is limited to the first part, i.e. Strategic Thinking. Recommendations for the bank in dealing with the fintech's "Cash Burn" strategy are also provided. To measure the readiness of employees in facing digital transformation surveys are carried out and distributed to all employees. The gap analysis at the company's current condition vs ideally transformed was carried out by mixed research method, which consists of surveys, observations, and interviews. The Disruptive Business Model Map by Rogers is used as a strategy map. The elements contained in the strategy decision tool written by Rogers, namely The Disruptive Response Planner are used to choose the best decision. Digital transformation readiness questionnaire results showed that 2/3 of employees stated that the company was ready for digital transformation, while 1/3 still doubted readiness in all strategic thinking domains of CC-DIV. This result was further confirmed by interviews. From the observations it was found that the company had previously collaborated with fintech so that they remained relevant to the conditions needed by customers. The Application Programming Interface became the new business model of that bank to on which new channel and revenue stream were generated. Meanwhile, that bank has already put in place sharing programs for employees of the changing conditions from the analog to digital era. To maintain long sustainable profit, they have been socializing the importance of a lifelong learning culture to be kept up to date with customer needs. The bank has also collaborated with all fintechs in topping up of their digital money application and collaborated with customers to fulfil what they actually need. In addition to collaborating with consumers, including fintechs, there are 2 things that the bank can choose in facing digital giants, i.e. becoming disruptors themselves or by making their mobile application as a platform business model for all fintechs and existing old-fashion business models.
\end{abstract}

\section{Keywords - the digital tranformation playbook, collaboration}

\section{INTRODUCTION}

Basic economic principle applies to all individuals i.e. obtaining the most out of the least price. Consequently, a large number of customers are tempted to take on highly attractive offers available in the market by making payment through digital wallet services provided by financial technology (fintech) firms. Discount wars waged by fintechs, often known as "Cash Burn" Strategy [1], eventually encourage increasing number of consumers to seriously consider making various transactions available in the digital wallet's ecosystem. A significant number of customers who are "eager to try new things" have already effected payment of their monthly bills through these digital wallet ecosystems to take advantage of promotions offered. Therefore, the conventional banking industry that is "disrupted" in Indonesia needs to reassess their strategic thinking to examine all the pain points that are less attractive to customers when compared to that offered by the alternatives, i.e. the disruptors (fintech firms) [2].

A banking company in Indonesia (let's call it XYZ) has experienced a decline in growth in terms of the number of new customers signing up, especially that of individuals. That's why the banks' management has decided to carry out a digital transformation. Moreover, one of the benefits of digital transformation according to King is that it can reduce operational costs [3]

According to Rogers, digital transformation is essentially a change in strategy [2]. So that it needs to be studied, especially by companies established before the digital era, it is important for them to review their strategies in these domains: Customer, Competition, Data, Innovation and Value (CC-DIV).

"Customer" domain focuses on harnessing the untapped customer network to expand the breadth and depth of customer base. "Competition" focuses on the position of the company within the context of its direct (symmetrical) competitors as well as within the indirect, intersectoral (asymmetrical) competitors. "Data" domain deals with acquisitions, analyses and interpretation of critical customers' information. "Innovation" focuses on data driven innovations. Lastly, but not of least importance, is the "Value" which focuses on developing new business models and new products centred around real value propositions for its customers.

Organizational agility is another important aspect in the transformation process [2]. An organization may be considered to have possessed agility when all necessary changes in resource allocation, measured elements, and incentive schemes are executed in a practical manner leading to evident results. The scope of this paper is limited to strategic thinking of an incumbent that supports decision making in dealing with specific problem of declining growth in the face of an increasingly competitive market. 
Most fintechs have come up with disruptive business models even though they started with non-conventional business models that one does not intuitively associate with everyday conventional banking [3]. To determine whether a fintech has actually become a disruptor or at least possess a potential to be one in the near future, Rogers devised a tool called The Disruptive Business Model Map [4]. Inside there are 2 test questions which needs to be answered. The first question: Does the business model of the Challenger displaces the value offered by incumbent, thereby rendering the incumbent's value obsolete? When the challenger is able to become a substitute for incumbent service, there is a real possibility that the challenger will become a disrupter. The other question: Whether incumbents or any other party can easily mimic or imitate the challenger's business model? If the incumbent is not able to quickly and easily develop a similar business model to the challenger's, then the challenger is really a disruptor.

Faced with a grim outlook, especially when dealing with disruptors, an incumbent must carefully formulate a plan of action and execute them decisively. The short term goal may include sustaining its current business model by strengthening its position in other sectors that are currently not (yet) disrupted by challengers. Examples in the banking sector are steps taken by XYZ bank by collaborating with all parties in financial technology and securing positions by strengthening their existing business by providing solutions to the needs of customers.

\section{Methodology}

\section{A. Mixed Method}

The mixed method is chosen to achieve balance between a high level picture of the company and an in-depth analysis. The type of triangulation used is the method triangulation [5]. To gauge the general perception of readiness for digital transformation, survey data were collected at the beginning of the study, which basically examines the readiness of digital transformation. Mixed methodologies is critical in this research, when the result of just one particular method (adopted from Digital Transformation Playbook) does not faithfully reflect the true picture of the subject matter.

Survey taken in this research showed that the Company is ready in all domains of strategic thinking and organizational agility. To balance this result with the other two research methods the Likert scale had been expanded to include scores of " 6 " and "7" which correspond to the state of Company being truly ready, and scores of " 5 " and below corresponding to the opposite.

These measures were taken in consideration of the existing organizational "inertia" (which has been addressed by compulsory further learning programs for employees). Results are processed and analysed using a quantitative methodology. The source of research data is all company employees.

\section{B. Survey}

The list of survey questions comes from the book Digital Transformation Playbook. To assess the readiness of digital transformation by surveying, Likert Scale is chosen, where values from 6 through 7 represent a generally positive answer and other values represent negative answer to the question. We modified the survey's interpretation of employees' readiness perceptions of Digital Transformation, because if scale 5 was considered ready we could not distinguish the least prepared domain.

\section{Direct Interview}

The other data collecting method in this research is that of direct interviews, especially with company's management officers and by structuring the interviews within the framework of Customer, Competition, Data, Innovation, Value domains.

\section{Observation}

At the same time using observations to double-check the actual conditions compared to the results obtained from the results of the readiness survey. Whereas data processing uses the quality methodology when conducting gap analysis with ideal conditions. The same data collection methods are also used when analysing business model maps and analysing strategic decisions that will be carried out by companies in dealing with fintech.

\section{RESULTS AND DISCUSSION}

Results of the questionnaire from all employees showed that roughly $67 \%$ of respondents were convinced of the Company's readiness for transformation, while the rest had doubts about Company's readiness. Most respondents belonging the former pointed out facts that support their opinion, such as:

\section{A. Become the Disrupter}

Acquisition of a start-up company, Synergy Aggregator, to stay current and on top of new innovations, both internally within the company and externally, including those of fintech who have registered their applications on the Google Playstore $^{\mathrm{TM}}$ or Apple Applicationtore ${ }^{\mathrm{TM}}$.

Launching its own products is made possible since it has unified all digital money top ups by utilizing its mobile banking platform. The company has collaborated with third parties to generate new revenue streams, thanks to the Application Programming Interface. With an administrative fee of 1,000 Rupiah, it is the amount of money that feels comfortable being received by the customers while also being income from the new business model obtained by the company.

\section{B. Loss Mitigation}

The company focuses on coming back to sustainable segments. The company establishes direct communication with all generations of prospective customers because it establishes communication utilizing the most popular communication following the latest trends. For example, via call centres via telephone, chat via call centres on the website, via the biggest 
chat services such as WhatsApp, LINE, and well-known social media applications. So that companies can realize the company's vision and mission to always be relevant to customer needs. At the same time ensuring long-term sustainability in the digital era that continues to change more and more quickly.

Portfolio diversification is carried out by instilling in employees a culture of learning using all channels in the digital age, for example in the form of e-learning, gamification, audio podcasts, etc., and continuous innovation continues to be developed from internal and external of the company. Innovation Competition is carried out through the knowledge sharing from each small group, while externally it is help in the hackathons competition, as well as the accelerator and aggregator.

\section{Example of Application of Digital Transformation Tools}

Associated with competition with fintech, which offers payment services at a discount, resulting in decreased customer growth, especially individuals who are accustomed to making payment transactions, the company needs to maintain innovation by providing convenience while looking for new customers to replace customers who are happy to try new things. The Digital Transformation Playbook [4], has provided related elements in analysing the strategic thinking of aspects of the Customer. The following "Table 1" is an example of the application in the analysis of changing customer needs. To capture new customers, companies need to consider the development of demographics, namely the development of Generation Z, born in the digital age. The following thoughts on the importance of introducing company services since prospective customers are currently still in the stages of schooling. Companies can do with collaboration; it is recommended the company conducts education with the manager of formal education.

TABLE I. CUSTOMER NETWORK STRATEGY GENERATOR

\begin{tabular}{|c|c|}
\hline \multicolumn{2}{|r|}{ Objective setting } \\
\hline $\begin{array}{l}\text { Direct objective } \\
\text { Increase the number of customers to } 30 \\
\text { million in } 3 \text { years }\end{array}$ & $\begin{array}{l}\text { Higher-order objectives } \\
\text { Being the first choice of enterprise society }\end{array}$ \\
\hline \multicolumn{2}{|l|}{ Customer selection \& focusing } \\
\hline \multicolumn{2}{|l|}{$\begin{array}{l}\text { Segment } \\
\text { Gen z }\end{array}$} \\
\hline & $\begin{array}{l}\text { The main purpose: customer type linchpin advocacy customer } \\
\text { Value proposition: XYZ always by your side } \\
\text { Barriers: limited customer network in public schools } \\
\text { Asymmetrical competitor of super application } \\
\text { Symmetrical competitors: other banking institutions }\end{array}$ \\
\hline \multicolumn{2}{|r|}{ Strategy selection } \\
\hline $\begin{array}{l}\text { Access } \\
\text { Gen } z\end{array}$ & $\begin{array}{l}\text { XYZ prepares a group on social media to form a gen } \mathrm{z} \text { community (elementary, junior high, high school } \\
\text { students) and alumni millenials for each secondary school in collaboration with every private and public } \\
\text { school in major cities throughout Indonesia. }\end{array}$ \\
\hline $\begin{array}{l}\text { Engage } \\
\text { Gen z }\end{array}$ & XYZ provides interesting content on each school agenda \\
\hline $\begin{array}{l}\text { Customize } \\
\text { Gen z }\end{array}$ & Provides menu options and features that can be customized according to customer preferences \\
\hline $\begin{array}{l}\text { Connect } \\
\text { Gen z }\end{array}$ & XYZ provides valuable programs such as cheap book exchanges on the XYZ digital money application. \\
\hline $\begin{array}{l}\text { Collaborate } \\
\text { Gen z }\end{array}$ & $\begin{array}{l}\text { XYZ offers prizes at event examples: "PenSi" competitions (art performances) and making thematic } \\
\text { videos \#XYZ always beside me and share on social media }\end{array}$ \\
\hline \multicolumn{2}{|r|}{ Concept generation } \\
\hline \multicolumn{2}{|c|}{ Define Impact } \\
\hline
\end{tabular}

\section{CONCLUSION}

A third of respondents had the opinion that the Company was not ready for transformation in the domains of Innovation and Data. Whereas in the domains of Customer, Value, and Competition are perceived as Ready by more than a quarter of respondents. Therefore, there needs to be extra efforts by Company management to prepare employees to possess digital strategic mind-set and skill set. More than a third of the sample respondents had a perception that the company had a poor record in terms of organizational agility, especially in the incentives and elements measured as well as adjusting the value proposition according to changes in customer behaviour and incorporating business innovation in the assessment.
Take the example of collaboration between Apple and Samsung, it is advisable for XYZ to collaborate with fintechs for mutual benefits by way of developing digital technologies. For example, to improve customer behaviour data and establish relationships with customers, $\mathrm{XYZ}$ is advised to create their own business model type of exchange platform on XYZ mobile that combines services to be embedded in customers' daily transactions. With the business model platform in mobile banking, it facilitates all types of customers to deal with one another. To support organizational agility, XYZ also needs to consider structural changes that encourage organizational culture such as financial technology that is lean, agile, and 
innovative, so that it can obtain sustainable profits in the digital age.

\section{REFERENCES}

[1] J. Surti, Startups and "Cash Burn" Strategies - What Separates the Good from the Bad? [Web log post] [Online]. Retrieved from: https://www.egnyte.com/blog/2014/12/startups-and-cash-burnstrategies-what-separates-the-good-from-the-bad/, 2014.
[2] J. Carter, What's a Pain Point? [Web log post] [Online]. Retrieved from: http://pointsandfigures.com/2012/04/27/whats-a-pain-point/, 2012.

[3] B. King, Bank 4.0 : Banking Everywhere, Never at a Bank. Singapore: Marshall Cavendish Business, 2018.

[4] D.L. Rogers, The Digital Transformation Playbook - Rethink your business for the digital age. Adobe Digital Editions, 2016.

[5] U. Sekaran and R. Bougie, Research methods for business: A skill building approach. John Wiley \& Sons, 2016. 